\title{
Membrane Fluidity in Human and Mouse Chediak-Higashi Leukocytes
}

\author{
Richard A. HaAk, Leah M. INGRaham, Robert L. Baehner, and \\ LAURENCE A. BoXer, Department of Microbiology and Immunology and \\ Department of Pediatrics, Indiana University School of Medicine, Indianapolis, \\ Indiana 46223
}

\begin{abstract}
A B S T R A C T Polymorphonuclear leukocytes from humans and mice with the Chediak-Higashi syndrome were characterized by spin label electron spin resonance spectrometry. Our results suggest that cells from afflicted mice and humans have membranes more fluid than controls. Order parameters for a spin label that probes near the membrane surface were 0.652 for normals and 0.645 for two Chediak-Higashi patients. Cells from Chediak-Higashi mice showed similar differences, as did isolated plasma membrane fractions. An increased membrane fluidity was also detected with a spin label that probes deeper in the bilayer. In vitro treatment of Chediak-Higashi mouse cells with $0.01 \mathrm{M}$ ascorbate increased the order parameter to normal levels. In vitro incubation of mouse Chediak-Higashi cells with glucose oxidase increased the order parameter, similar to the effect of ascorbate. This increase was abolished when catalase was added to the incubation medium. In vitro incubation with dibutyryl cyclic guanosine monophosphate $(1 \mu \mathrm{M}$ to $0.1 \mathrm{mM})$ did not normalize order parameters. These results indicate that fluidity of Chediak-Higashi cell membranes was affected by treatments expected to alter the oxidation: reduction potential of the environment but was not affected by treatments expected to alter the ratio of intracellular cyclic nucleotides. The latter treatment would affect microtubule assembly. Therefore, it appears that the membrane fluidity abnormalities as demonstrated by electron spin resonance and the earlier demonstrated microtubule dysfunctions characteristic of Chediak-Higashi cells are coexisting defects and are probably not directly related.
\end{abstract}

This study was done during the tenure of Dr. Boxer as an Established Investigator of the American Heart Association. Received for publication 20 November 1978 and in revised form 15 February 1979.

\section{INTRODUCTION}

The Chediak-Higashi syndrome (CHS $)^{1}$ of man is an autosomal recessive disorder in which polymorphonuclear leukocytes (PMN) exhibit a variety of abnormalities (1). A similar disorder has been described in mice (2). Phenotypic characteristics of the syndrome include: $(a)$ decreased pigmentation brought about by aggregation of melanin granules; $(b)$ enlarged lysosomes; and $(c)$ recurrent problems with bacterial infections secondary to disorders of PMN chemotaxis, degranulation, adherence, and bacterial killing. Treatment with ascorbate corrects these functional defects of CHS PMN (3-5).

Membrane abnormalities may contribute to these various defects. Concanavalin A (Con A) treatment of CHS PMN reveals spontaneous formation of polar caps of surface glycoproteins $(6,7)$, suggesting that these cells have abnormal mobility of membrane constituents. Normal cells do not undergo capping unless treated with colchicine, which inhibits microtubule (MT) assembly. Thus, membrane alterations in CHS may coexist along with MT dysfunction or they may be directly related to it.

In this study we have used spin label electron spin resonance (ESR) spectrometry to characterize abnormalities in CHS PMN membranes. Our results indicate that these cells from CHS mice have an altered membrane environment compared to those from normal animals. Further, study of PMN from patients with CHS

\footnotetext{
${ }^{1}$ Abbreviations used in this paper: CAMP, cyclic AMP; CGMP, cyclic GMP; CHS, Chediak-Higashi syndrome; Con A, concanavalin A; ESR, electron spin resonance; G, gauss; HBG, modified Hanks' solution described in reference 8; MT, microtubules; PMN, polymorphonuclear leukocytes; 5DS, 2-(3-carboxypropyl)-4,4-dimethyl-2-tridecyl-3-oxazolidinyloxyl; 12DS, 2-(10-carboxydecyl)-2-hexyl-4,4dimethyl-3-oxazolidinyloxyl.
} 
suggests that this same membrane alteration occurs in human cells.

\section{METHODS}

Chemicals. Dibutyryl cyclic GMP (cGMP), glucose oxidase, and catalase were obtained from Sigma Chemical Co. (St. Louis, Mo.). The spin labels (Fig. 1) 2-(3-carboxypropyl)-4,4-dimethyl-2-tridecyl-3-oxazolidinyloxyl (5DS) and 2-(10-carboxydecyl)-2-hexyl-4,4-dimethyl-3-oxazolidinyloxyl (12DS) were purchased from Syva (Palo Alto, Calif.). Stock solutions of spin labels at $5 \mathrm{mM}$ were made up in ethanol.

Animals. Normal (C576J $+/+$ ) and CHS (C576J bg/bg) mice were obtained from The Jackson Laboratory (Bar Harbor, Maine).

Human subjects. Two white female patients were studied. The diagnosis of CHS had been established by clinical history and examination and in the presence of giant lysosomes in PMN. Reports of the success of ascorbic acid therapy with these patients have been made $(3,5)$. Before the present ESR studies ( 2 mo for patient $1 ; 5 \mathrm{wk}$ for patient 2 ) ascorbic acid treatment had been discontinued as a check on the continued efficacy of this therapeutic approach. Degranulation, bacterial killing, and chemotaxis have been demonstrated to return to abnormal levels $4 \mathrm{wk}$ after cessation of ascorbic acid therapy (3). Cells from normal white adult females were used as controls for our present investigation. Protocols involving human subjects were approved by the Indiana University/Purdue University-Indianapolis Committee on Protection of Human Subjects. Informed consent was obtained and the research was conducted according to the Declaration of Helsinki.

Preparation and incubation of PMN. Peritoneal exudate leukocytes were elicited from mice by intraperitoneal injection of 2-3 ml 12\% sodium caseinate (Difco Laboratories, Detroit, Mich.). $18 \mathrm{~h}$ after injection, mice were sacrificed and peritoneal contents collected. Cells were suspended in icecold $0.85 \% \mathrm{NaCl}$ and centrifuged $\left(200 \mathrm{~g}, 10 \mathrm{~min}, 4^{\circ} \mathrm{C}\right)$, re- suspended and washed twice in saline. Final suspension (3.5 to $4.5 \times 10^{7}$ leukocytes $/ \mathrm{ml}$ ) was in modified Hanks' solution (8) (HBG) with added glucose $(0.1 \%)$ and bovine serum albumin (0.01\%). Typically suspensions were $80-90 \%$ PMN. Human PMN were prepared from venous blood by dextran sedimentation and separation by Ficoll-Hypaque gradient (Pharmacia Fine Chemicals, Piscataway, N. J.) (9). Final suspension was in $\mathrm{HBG}$ at $3.0 \times 10^{7}$ leukocytes $/ \mathrm{ml}$ with $98 \%$ of cells being PMN.

$1 \mathrm{ml}$ PMN suspension was placed in a snap-cap tube. For some experiments additions of ascorbate, cGMP, glucose oxidase, or catalase were made. Controls received $\mathrm{HBG}$ in place of these agents. Incubation was carried out at $37^{\circ} \mathrm{C}$ for $15 \mathrm{~min}$ with tumbling ( $12 \mathrm{rpm})$. In experiments with ascorbate, cells were washed with $9 \mathrm{ml} \mathrm{HBG}$ after incubation and resuspended in $1 \mathrm{ml} \mathrm{HBG}$ after centrifugation $\left(200 \mathrm{~g}, 5 \mathrm{~min}, 20^{\circ} \mathrm{C}\right)$.

PMN membrane fractions. Mouse peritoneal PMN collected as described above were suspended in $10 \mathrm{mM} \mathrm{Tris} \cdot \mathrm{HCl}$ ( 2 vol buffer to 1 vol cell pellet), $\mathrm{pH} 7.4$, containing $0.25 \mathrm{M}$ sucrose $(8.3 \%$ sucrose). The cells were homogenized in a Dounce homogenizer (Kontes Co., Vineland, N. J.) until $90 \%$ of the cells were disrupted as monitored by phase microscopy and then centrifuged at $600 \mathrm{~g}$, at $4^{\circ} \mathrm{C}$ for $10 \mathrm{~min}$ to remove unbroken cells, debris, and intact nuclei. The supernate was layered on a sucrose gradient composed of successive layers of 30,40 , and $50 \%$ sucrose. The tubes were centrifuged at $30,000 \mathrm{rpm}(111,000 \mathrm{~g})$ in a Beckman S. W. 41 rotor (Beckman Instruments, Inc., Spinco Div., Palo Alto, Calif.) for $5 \mathrm{~h}$ at $4^{\circ} \mathrm{C}$. The bands at the interfaces between 8.3 and $30 \%, 30$ and $40 \%$, and 40 and $50 \%$ were collected and washed in $25 \mathrm{ml}$ ice-cold distilled water. Assays were performed for 5 '-nucleotidase as plasma membrane marker (10), beta glucuronidase (3) and lysozyme (Worthington kit No. 27978; Worthington Biochemical Corp., Freehold, N. J.) as granule markers, and glucose-6-phosphatase as microsomal marker (11). The $8.3 / 30 \%$ interface band showed a 10 -fold enrichment for 5'-nucleotidase as compared to the original supernate, and $>50 \%$ of total activity of this enzyme was

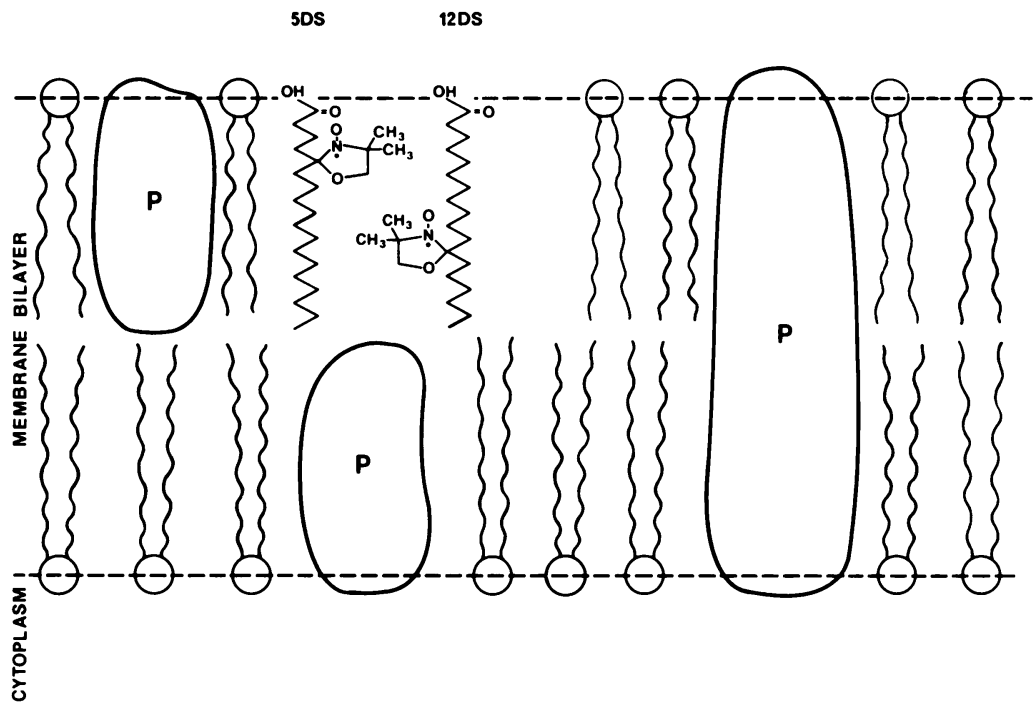

FIGURE 1 Diagrammatic representation of a generalized membrane. Proteins $(\mathrm{P})$ and phospholipids $(\xi)$ are indicated along with the structures and probable locations of the spin labels used in this study. The stearic acid analogs, 5DS and 12DS, probe different levels of the membrane interior. 
located in this fraction. Little enrichment $(\leqq 4 \%$ for the granule or microsomal markers were located in the 8.3 / $30 \%$ band.

Spin labeling. Fig. 1 shows the spin labels, 5DS and 12DS, and their orientation in the membrane. The former has the nitroxide "reporter" group near the membrane surface, whereas the latter reports from deeper within the bilayer. The amphophilic nature of these molecules determines their vertical position in the bilayer. The hyperfine coupling constants for labeled cells were consistent with the location shown in Fig. 1.

For labeling intact cells "label tubes" were prepared by addition of $8 \mu$ l 5DS or $15 \mu$ l 12DS stock solution; the solvent was evaporated under a stream of $\mathrm{N}_{2}$ gas to provide a thin film of label in the bottom of each tube. The PMN suspension was transferred to a label tube. After $5 \mathrm{~min}$ at $20^{\circ} \mathrm{C}$, the labeled PMN were centrifuged $\left(40 \mathrm{~s}, 400 \mathrm{~g}, 20^{\circ} \mathrm{C}\right)$ into the sealed tip of a Pasteur pipette and the ESR spectrum of the pellet was recorded. Effects of spin labeling on viability of PMN were determined by trypan blue exclusion. Cell suspensions labeled with either 5DS or 12DS were $95 \%$ viable.

Membrane fractions were suspended in Krebs-Ringers phosphate at a concentration of $\cong 40 \mathrm{mg}$ protein $/ \mathrm{ml}$. A 30 $\mu$ l sample of membrane was labeled by placing it in a glass tube in which $3 \mu$ l of stock 5DS had previously been evaporated. The membrane was taken up in a $100-\mu l$ capillary, and the distal tip of the capillary was heat sealed and cooled. After centrifugation to displace the membranes into the sealed tip, the tube was placed in the ESR spectrometer and the spectrum recorded.

ESR data acquisition and analysis. ESR spectra were obtained on a standard balanced-bridge spectrometer with diode detection operating at $9.1 \mathrm{GHz}$. Phase-sensitive detection with a $50-\mathrm{kHz}$ magnetic field modulation frequency was used. Sample heating and broadening of spectral lines were avoided by recording all spectra at low microwave power $(12 \mathrm{~mW})$ incident on the Varian V4535 large access cavity (Varian Associates, Palo Alto, Calif.). A peak-to-peak modulation amplitude of 1.5 gauss $(G)$ was used for 5DS-labeled PMN and $0.5 \mathrm{G}$ for 12DS-labeled cells. Other appropriate values were sometimes used after determination that comparisons between samples were independent of amplitude at the values used. All instrument settings were identical for a particular set of samples being compared. First derivative absorption spectra were recorded with a $100-G$ field sweep, a scan time of $5 \mathrm{~min}$, and a time constant of $0.2 \mathrm{~s}$. The magnetic field sweep was calibrated with a NMR gaussmeter (Varian Associates, Palo Alto, Calif.). Sample temperature was monitored with a thermocouple, and was maintained to within $\pm 0.5^{\circ} \mathrm{C}$ of the desired temperature (usually $25^{\circ} \mathrm{C}$ ) through use of a chilled or heated $\mathrm{N}_{2}$ gas-flow system.

Two spectra from each sample were recorded and the resultant parameters averaged. All samples were coded and read blind. For experiments in which identical samples were run on the same day, the standard procedures for determining mean, $\mathrm{S}$ error, and SD were used. For experiments in which several samples were measured and data from several days were available, a two-way analysis of variance was carried out. All $\boldsymbol{P}$ values given herein are for the probability that a null hypothesis is true.

The order parameter (S), a measure of spin label order and motion, was calculated $(12,13)$ for 5DS-labeled PMN.

$$
S=\frac{T_{\|}-T_{\perp}^{\prime}-C}{T_{\|}+2 T_{\perp}^{\prime}+2 C} \cdot 1.66,
$$

where $C=1.4-0.053\left(T_{\|}-T_{\perp}^{\prime}\right)$. The measurement of the hyperfine spitting parameters $T_{\|}\left(T\right.$ parallel) and $T_{\perp}^{\prime}\left(T^{\prime}\right.$ per- pendicular) from a typical ESR spectrum of 5DS-labeled PMN from Chediak-Higashi mice is shown in Fig. 2A. As flexibility of the hydrocarbon chain of the spin label decreases, the order parameter increases. This implies that as the environment surrounding the nitroxide group of the label becomes more ordered (i.e., less fluid), the order parameter increases. The theoretical limits of $S$ are $S=0$ for a completely fluid, isotropic system and $S=1$ for a completely rigid or ordered environment. Typical values for spin-labeled membranes are from 0.5 to 0.7 . Changes in $\mathrm{S}$ as small as $0.5 \%$ can be shown to be statistically significant at a $95 \%$ confidence level (14).

The class of spectra resulting from isotropic rapid motion of a spin label is most amenable to quantitative assessment by the calculation of the rotational correlation time, $\tau_{c}(15,16)$ :

$$
\tau_{\mathrm{c}}=\left(6 \times 10^{-10} \mathrm{~s} / \mathrm{G}\left(\mathrm{W}_{+1}\right)\left[\left(\mathrm{h}_{+1} / \mathrm{h}_{-1}\right)^{1 / 2}-1\right] .\right.
$$

The line-width and line-heights necessary for this calculation are obtained from the ESR spectrum as shown in Fig. 2B.
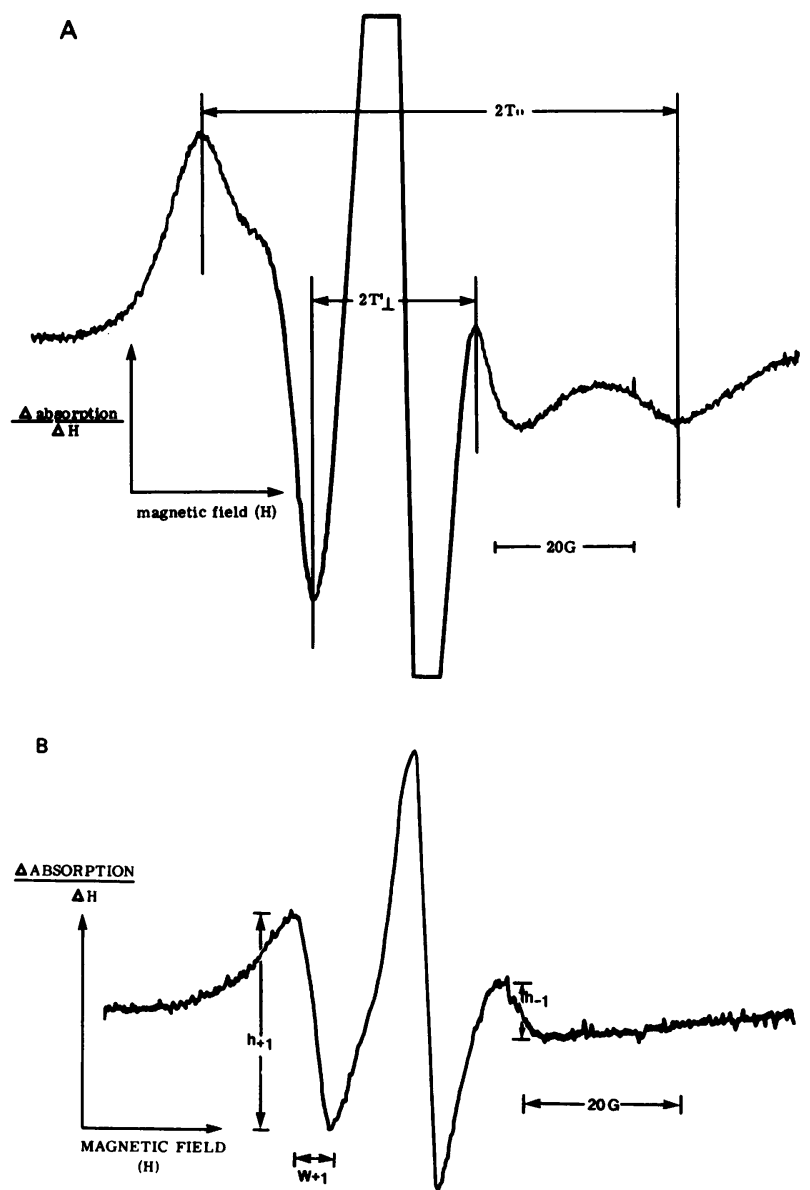

Figure 2 First derivative ESR spectrum at $25^{\circ} \mathrm{C}$ of spinlabeled PMN from Chediak-Higashi mice. (A) 5DS-labeled cells. The hyperfine splitting parameters $2 \mathrm{~T}_{\|}$and $2 \mathrm{~T}_{\perp}^{\prime}$ are the separation between outer and inner extrema respectively and are used in the calculation of order parameter (Eq. 1). (B) 12DS-labeled cells. The line-width $\mathrm{W}_{+1}$ and line-heights, $h_{+1}$ and $h_{-1}$, are used in calculation of a empirical motional parameter, $\mathbf{R}_{\mathbf{i}}$ (Eq. 3). 
However, the assumptions made in deriving Eq. 2 are completely satisfied only for rapid, isotropic motion $\left(\tau_{\mathrm{c}}<10^{-9} \mathrm{~s}\right)$. Because 12DS in P.MN membranes has a $\tau_{\mathrm{c}}$ near this limit and also probably has some anisotropic motion, for comparative purposes the 12DS results are reported with an operationally defined, empirical parameter, $\mathrm{R}_{\mathrm{i}}$ :

$$
R_{i}=\left(W_{+1}\right)\left[\left(h_{+1} / h_{-1}\right)^{1 / 2}-1\right]
$$

$R_{i}$ can be related to the degree of spin label motion in the membrane by noting that near $25^{\circ} \mathrm{C} \mathrm{R}_{\mathrm{i}}$ changes by $0.2 \mathrm{G} /{ }^{\circ} \mathrm{C}$. As the temperature increases, $R_{i}$ decreases; this suggests that the spin label motion is more rapid and that the membrane environment is more fluid.

\section{RESULTS}

PMN prepared from venous blood of human subjects were spin labeled with 5DS. In sets of paired samples, CHS cells consistently had a lower $\mathrm{S}$ than did normal cells (Fig. 3) $(P<0.065$ for patient $1 ; P<0.004$ for patient 2 ). The relatively large number of cells required for our determinations precluded intensive experimentation with PMN of these patients, but the similarity between their cells and those of the CHS mice encouraged us to use cells from these animals in studies designed to help elucidate the molecular and(or) subcellular basis for the fluidity difference.

Peritoneal exudate PMN from normal and CHS mice were labeled with 5DS. Results were similar to those obtained with human PMN; the comparison of order parameters revealed a significant difference $(P=0.003$;

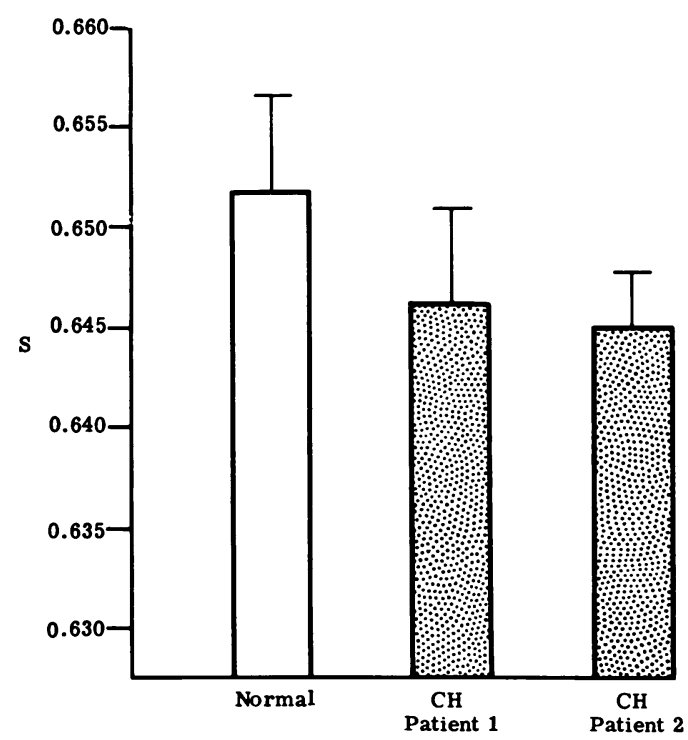

Figure 3 Order parameters at $23^{\circ} \mathrm{C}$ for $5 \mathrm{DS}$-labeled human PMN. Incubation and labeling conditions as described in Methods. Bars indicate $2 \mathrm{SE}$ above the mean. The difference between normal and Chediak-Higashi PMN is significant at $P<0.065$ for patient 1 and $<0.004$ for patient 2 . The number of observations for normal, patient 1 and patient 2 is 7,4 , and 3 , respectively.

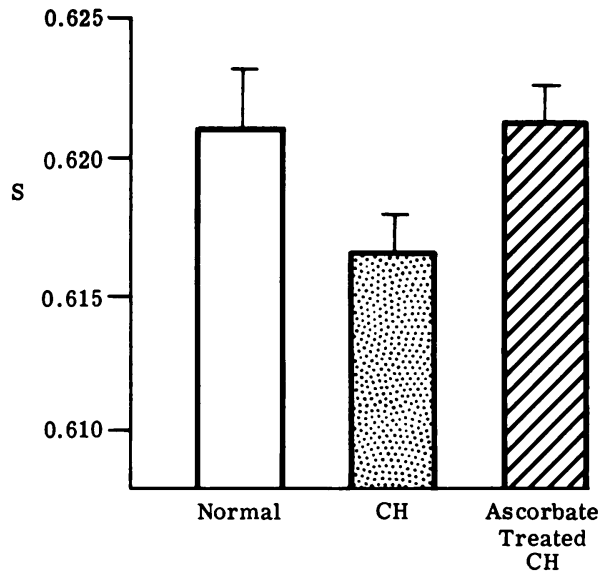

Figure 4 Order parameter at $25^{\circ} \mathrm{C}$ for 5DS-labeled PMN from normal and from Chediak-Higashi mice. Incubation and labeling conditions as described in Methods. Final concentration of ascorbate was $0.01 \mathrm{M}$. Bars indicate $2 \mathrm{SE}$ above the mean. Values are from analysis of nine or more samples from three separate experiments. The difference between normal and Chediak-Higashi PMN is significant at $P=0.003$, as is the difference between CHS and ascorbate-treated CHS cells.

Fig. 4). S for the Chediak-Higashi cells (0.616) was lower than that for normals (0.621), again suggesting that the former have greater membrane fluidity in the bilayer region probed by 5DS.

Comparison at $25^{\circ} \mathrm{C}$ of the two types of PMN labeled with $12 \mathrm{DS}$ also showed a significant $(P<0.004)$ difference (Fig. 5). For this label, values for the empirical motional parameter, $R_{i}$, were calculated. In this temperature range, $\mathrm{R}_{\mathrm{i}}$ decreases by $0.2 \mathrm{G} /{ }^{\circ} \mathrm{C}$ temperature increase. The lower value for $R_{i}$ from PMN of CHS mice thus suggests that the lipid molecules within the membrane at the level probed by 12DS had more freedom of motion than do those of normal cells.

Membraneous material isolated from homogenized

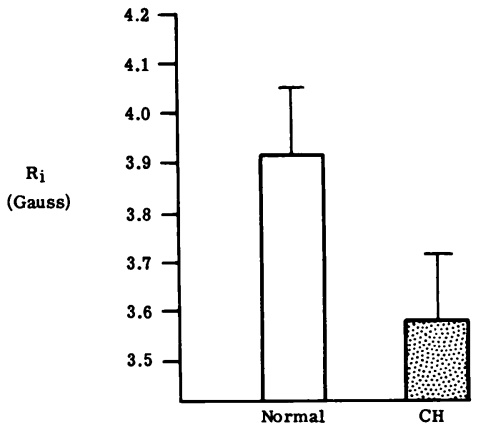

Figure $5 \quad R_{i}$ (Eq. 3) at $25^{\circ} \mathrm{C}$ for 12DS-labeled PMN from normal and from Chediak-Higashi mice. Incubation and labeling conditions as described in Methods. Values are from analysis of eight samples each from two experiments. Bars indicate $2 \mathrm{SE}$ above the mean. The difference between normal and Chediak-Higashi PMN is significant at $P<0.004$. 
mouse peritoneal PMN was labeled with 5DS. The S value for the CHS membrane fraction that banded at the $8.3 / 30 \%$ sucrose interface was 0.648 (average of two separate determinations), whereas that for the same fraction from normal animals was 0.659 . This fraction was significantly enriched for the plasma membrane marker 5'-nucleotidase and showed little enrichment for granule or microsomal markers (Methods). We therefore conclude that the lower order parameter observed for intact CHS PMN as compared to intact normal $P M N$ is due, at least in part, to differences in the plasma membrane fluidity of the two cell types.

Ascorbate treatment of some CHS patients $(4,5)$ has led to normalized in vitro function of PMN, which has coincided with a marked diminuation of clinically apparent bacterial infections. We were interested, therefore, in examining the effect ascorbic acid might have on the abnormal membrane fluidity of CHS PMN. Incubation of 5DS-labeled CHS mouse PMN with $0.01 \mathrm{M}$ ascorbate increased their order parameter $(P<0.003$; Fig. 4) compared to untreated CHS PMN. The values were not significantly different $(P=0.92)$ from those for cells from normal mice. Ascorbate treatment of normal cells did not alter their $\mathrm{S}$.

To explore the possibility that evolution of $\mathrm{H}_{2} \mathrm{O}_{2}$ might be altering fluidity of ascorbate-treated CHS PMN, we incubated cells with glucose oxidase under conditions which should permit $\mathrm{H}_{2} \mathrm{O}_{2}$ generation. Fig. 6 shows the results of these experiments. In the presence of heat-inactivated enzyme the CHS PMN were more fluid than normal cells. Incubation with active glucose oxidase $(1 \mathrm{U} / \mathrm{ml})$ increased CHS S values $(P<0.001)$ compared to untreated CHS cells. They were not significantly different $(P>0.5)$ from untreated normal cells. Such treatment with glucose

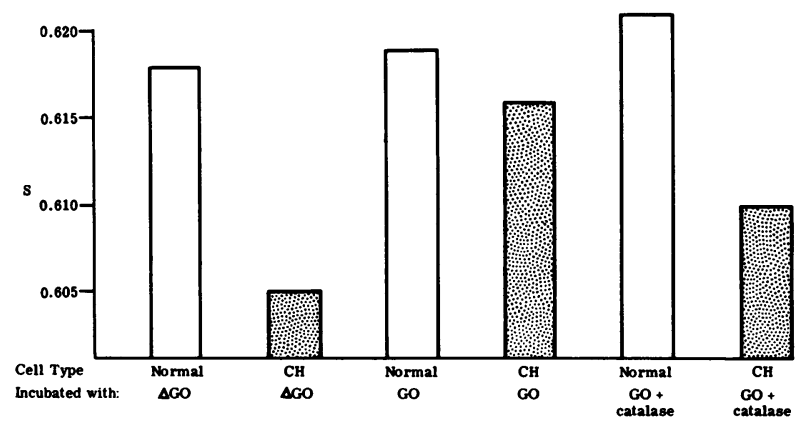

FIGURE 6 Order parameters at $25^{\circ} \mathrm{C}$ for $5 \mathrm{DS}$-labeled mouse $P M N$ incubated in the presence of glucose oxidase. Amount of reagents were: $1 \mathrm{U} / \mathrm{ml}$ of glucose oxidase; $1,500 \mathrm{U} / \mathrm{ml}$ of catalase. Heated glucose oxidase was prepared by incubation of enzyme at $100^{\circ} \mathrm{C}$ for $30 \mathrm{~min}$. Values are from analysis of four or more samples from two separate experiments. The difference between Chediak-Higashi cells incubated with heated glucose oxidase and those incubated with active glucose oxidase is significant at $P<0.001$. oxidase had no significant effect $(P>0.75)$ on normal cells. Further, incubation of CHS cells with active glucose oxidase and catalase $(1,500 \mathrm{U} / \mathrm{ml})$, conditions that would reduce the level of $\mathrm{H}_{2} \mathrm{O}_{2}$, had little effect on these cells and their $\mathrm{S}$ value were again lower than those of similarly treated normal cells.

The effect of changes in intracellular levels of a cyclic nucleotide and a microtubule disrupting agent was also examined. The addition of cGMP $(0.1 \mathrm{mM}$ to $1 \mu \mathrm{M})$ to 5DS-labeled PMN from normal and from CHS mice had no significant effect on $S$ (Table I). Similarly, incubation of cells with colchicine $(0.1 \mathrm{mM}$ to $1 \mu \mathrm{M}$ ) for $30 \mathrm{~min}$ failed to affect significantly the order parameter (data not shown).

\section{DISCUSSION}

Study of cell membrane fluidity in various disease states has received increasing attention in recent years (17). Fluorescence polarization studies of leukemic lymphocytes (18) and ESR studies of erythrocytes from muscular dystrophy patients $(19,20)$ have revealed fluidity abnormalities for these formed elements of the blood. In this study we have used spin label ESR to characterize the membrane fluidity of intact, viable CHS PMN and isolated membrane fractions. Our results suggest that CHS PMN from humans and mice have membranes more fluid that controls. In addition, we modified the membrane fluidity of the CHS PMN in vitro with the addition of ascorbate and a $\mathrm{H}_{2} \mathrm{O}_{2}$ generating system. These effects were observed only in CHS cells and not in the normal controls, which demonstrates that the CHS membranes have altered properties allowing them to respond differently to oxidase treatments. Although ascorbate modified the PMN membrane fluidity in vitro its effect on enhancing PMN function in vivo in CHS patients may be coincidental.

TABLE I

Effect of cGMP on Order Parameter of 5DS-labeled Mouse PMN

\begin{tabular}{lcc}
\hline \multirow{2}{*}{ Treatment } & \multicolumn{2}{c}{ Order parameter* } \\
\cline { 2 - 3 } & Normal PMN & Chediak-Higashi PMN \\
\hline None & 0.619 & 0.613 \\
$1 \mu$ M cGMP & 0.618 & 0.611 \\
$10 \mu$ M cGMP & 0.617 & 0.612 \\
$0.1 \mathrm{mM} \mathrm{cGMP}$ & 0.619 & 0.612 \\
\hline
\end{tabular}

Values are means from analysis of six or more samples from three separate experiments. $2 \mathrm{SE}$ correspond to approximately 0.003 for each entry. For untreated PMN, the difference between normal and Chediak-Higashi is significant at $P<0.08$. * Conditions of incubation and labeling as described in Methods. 
The increase in membrane fluidity observed in CHS PMN membrane could be caused by many factors. Those of particular pertinence to the CHS include decreased cholesterol content, a decreased sphingomyelin:lecithin ratio, and an increased degree of unsaturation of membrane fatty acids. A decreased total cholesterol level in the fasting serum of one CHS patient has been reported (21). Through exchange processes this serum decrease may be reflected in a similar decrease of membrane cholesterol levels. Decreased cholesterol content would be expected to give rise to increased membrane fluidity (17) such as we report here. An accelerated turnover of sphingolipids in CHS leukocytes has been demonstrated (22), and is consistent with previous reports of a decreased sphingolipid content in CHS PMN membrane (23) and in serum (21). This decrease, together with the reported concurrent increase in lecithin content (21), would be expected to give rise to increased membrane fluidity.

Molecular movements within the membrane seem critical to many cellular functions. The lower $S$ values for CHS PMN may reflect the same membrane alterations that lead to the abnormal fusion of azurophilic and specific granules $(24,25)$ found in these cells. Disordered fluid portions of the membrane may favor fusion. Lucy (26) has suggested that factors which bring about localized regions of micellular lipid arrangements in the bilayer will also favor membrane fusion.

In vitro ascorbate treatment might have resulted in a decrease in membrane fluidity in CHS PMN through a variety of mechanisms. Studies with cells in culture have previously suggested that ascorbate-triggered reactions led to production of $\mathrm{H}_{2} \mathrm{O}_{2}$, which in turn was responsible for membrane alteration (27). Membranes of PMN high in unsaturated fatty acid content, specifically of arachidonic acid, have greater susceptibility to lipid peroxidation (28). In phospholipid liposomes ascorbate-induced lipid peroxidation has been shown to increase membrane rigidity (29). If, as we presently believe, the ascorbate effects on CHS fluidity are mediated via $\mathrm{H}_{2} \mathrm{O}_{2}$, a likely biochemical mechanism is lipid peroxidation and the likely targets include unsaturated fatty acids. Whatever the mechanism, the absence of a marked response to ascorbate treatment by normal PMN, in contrast to CHS PMN, suggests that initially more fluid membranes of CHS cells have an altered in vitro structure or organization which may be the basis, at least in part, of altered function in vivo.

An alternate mechanism for ascorbate effect on fluidity might be related to changes in intracellular levels of cyclic nucleotides. Earlier studies had demonstrated that ascorbate treatment resulted in partial correction of the elevated cAMP levels in human CHS cells $(3,5)$. Treatment of CHS PMN of either human (30) or mouse (7) with cGMP also normalized function, and it therefore appeared that cAMP:cGMP ratios might be important in defect repairs. Incubation of $P M N$ in concentrations of cGMP up to $0.1 \mathrm{mM}$, however, had no significant effect on order parameters of either normal or CHS PMN. Thus, it appeared that participation of ascorbate in oxidation:reduction reactions was more important in altering the fluidity of CHS cells than was any effect related to potential alteration of intracellular cyclic nucleotides.

A role for MT in defects of CHS PMN has been suggested (7). PMN from CHS subjects undergo spontaneous capping of membrane glycolipids as revealed by treatment with Con $A(6,7)$. Normal cells show no such tendency unless incubated with agents that prevent MT assembly. Cyclic GMP treatment, which normalized capping in CHS cells $(6,7,30)$, also influenced functions in normal PMN that are colchicine-sensitive, such as lysosomal enzyme release (31). Electron microscopy revealed an absence of MT assembly in Con Atreated PMN from a CHS patient but normal MT assembly in CHS PMN incubated with cGMP and cholinergic agonists before Con A treatment (32). Thus, in these studies it appeared that CHS abnormalities were related to colchicine-binding structures, presumably MT.

On the other hand, giant lysosomes, pathonomic for CHS syndrome, persisted in human patients undergoing ascorbate therapy (24), and we have not detected any consistent effects of cGMP or colchicine on the fluidity of PMN from normal or CHS mice. In addition, a recent study of capping in various mammalian cells suggests no clear role for MT (33). It appears that the membrane fluidity abnormalities as demonstrated by electron spin resonance and the earlier demonstrated microtubule dysfunctions characteristic of Chediak-Higashi cells are coexisting defects and are probably not directly related. However, the possible relations among abnormal MT, altered membrane properties, and defective PMN function in CHS remain to be elucidated.

\section{ACKNOWLEDGMENTS}

The authors gratefully acknowledge J. M. Allen and M. Stine for expert technical assistance and thank F. W. Kleinhans and W. D. Sawyer for helpful discussion.

This work was supported in part by National Institutes of Health grant PHS ROI 13586-03, a grant from Indiana Elks and a Biomedical Research Grant from Indiana University School of Medicine. ESR data were obtained at the Department of Physics, Indiana University/Purdue UniversityIndianapolis.

\section{REFERENCES}

1. Blume, R. S., and S. M. Wolff. 1972. The ChediakHigashi syndrome: studies in four patients and a review of the literature. Medicine (Baltimore). 51: 247-280.

2. Gallin, J. I., J. S. Bujak, E. Patten, and S. M. Wolff. 1974. 
Granulocyte function in Chediak-Higashi syndrome of mice. Blood. 43: 201-206.

3. Boxer, L. A., A. M. Watanable, M. Rister, H. R. Besch, J. Allen, and R. L. Baehner. 1976. Correction of leukocyte function in Chediak-Higashi syndrome by ascorbate. N. Engl. J. Med. 295: 1041-1045.

4. Boxer, L. A., J. M. Allen, A. M. Watanabe, H. R. Besch, and R. L. Baehner. 1978. Role of microtubules in granulocyte adherence. Blood. 51: 1045-1050.

5. Boxer, L. A., D. F. Albertini, R. L. Baehner, and J. M. Oliver. 1979. Impaired microtubule assembly and polymorphonuclear leukocyte function in the ChediakHigashi Syndrome correctable by ascorbic acid. $B r . J$. Hematol In press.

6. Oliver, J. M., R. B. Zurier, and R. D. Berlin. 1975. Conconavalin A cap formation on polymorphonuclear leukocytes of normal and beige (Chediak-Higashi) mice. $\mathrm{Na}$ ture (Lond.). 253: 471-473.

7. Oliver, J. M., and R. B. Zurier. 1976. Correction of characteristic abnormalities of microtubule function and granule morphology in Chediak-Higashi syndrome with cholinergic agonists. Studies in vitro in man and in vivo in the beige mouse. J. Clin. Invest. 57: 1239-1247.

8. Martin, S. P., and R. Green. 1958. Methods for the study of surviving leukocytes. A. Preparation of cell suspensions. Methods Med. Res. 7: 136-138.

9. Boyum, A. 1968. Separation of leukocytes from blood and bone marrow. Scand. J. Clin. Lab Invest. Suppl. 21: 77-89.

10. Avruck, J., and D. F. H. Wallach. 1971. Preparation and properties of plasma membrane and endoplasmic reticulum fragments from isolated rat fat cells. Biochim. Biophys. Acta. 233: 344-347.

11. Bagenski, E. S., P. P. Foa, and B. Zak. 1974. Glucose6-phosphatase. In Methods of Enzymatic Analysis. H. U. Bergmeyer, editor. Academic Press, Inc., New York. 876.

12. Gaffney, B. J., and C. M. McNamee. 1974. Spin-label measurements in membranes. Methods Enzymol. 323: 161-198.

13. Berliner, L. J. 1976. Spin labeling: Theory and Applications. Academic Press, Inc., New York. 592 pp.

14. Kury, P. G., and H. M. McConnell. 1975. Regulation of membrane flexibility in human erythrocytes. Biochemistry. 14: 2798-2502.

15. Kivelson, D. 1960. Theory of ESR linewidths of free radicals. J. Chem. Phys. 33: $1094-1106$.

16. Stone, T. J., T. Buckman, P. L. Nordio, and H. M. McConnell. 1965. Spin-labeled biomolecules. Proc. Natl. Acad. Sci. U. S. A. 54: 1010-1017.

17. Cooper, R. A. 1977. Abnormalities of cell-membrane fluidity in the pathogenesis of disease. N. Engl. J. Med. 297: 371-377.

18. Inbar, M., R. Goldman, L. Inbar, I. Bursuker, B. Goldman, E. Akstein, P. Segal, E. Ipp, and I. BenBassat. 1977. Fluidity differences of membrane lipids in human and leukemic lymphocytes as controlled by serum components. Cancer Res. 37: 3037-3041.

19. Butterfield, D. A. 1977. Electron spin resonance studies of erythrocyte membranes in muscular dystrophy. Acc. Chem. Res. 10: 111-116.

20. Sato, B., K. Nishikida, L. T. Samuels, and F. H. Tyler. 1978. Electron spin resonance studies of erythrocytes from patients with Duchenne muscular dystrophy. $J$. Clin. Invest. 61: 251-259.

21. Kritzler, R. A., J. Y. Terner, J. Lindenbaum, J. Magidson, R. Williams, R. Preisig, and G. B. Phillips. 1964. ChediakHigashi syndrome. Cytologic and serum lipid observations in a case and family. Am. J. Med. 36: 583-594.

22. Kanfer, J. N., R. S. Blume, R. A. Yankee, and S. M. Wolff. 1968. Alteration of sphingolipid metabolism in leukocytes from patients with the Chediak-Higashi syndrome. $N$. Engl. J. Med. 279: 410-413.

23. Kanfer, J. N., R. Richards, J. P. Kampine, S. Handmaker, and R. A. Yankee. 1967. Alteration of the sphingolipid content in leukocytes from patients with ChediakHigashi syndrome. Life Sci. 6: 2661-2664.

24. Rausch, P. G., K. B. Pryzwansky, and J. K. Spitznagel. 1978. Immunocytochemical identification of azurophilic and specific granule markers in the giant granules of Chediak-Higashi neutrophils. N. Engl. J. Med. 298: 693-698.

25. Rozenszajn, L. A., E. B. David, and S. B. Sela. 1977. Large granules and lysosomal fusion in human Chediak-Higashi white blood cells. Acta Haematol. (Basel). 57: 279-289.

26. Lucy, J. A. 1970. The fusion of biological membranes. Nature (Lond.). 227: 815-817.

27. Peterkofsky, B., and W. Prather. 1977. Cytotoxicity of ascorbate and other reducing agents towards cultured fibroblasts as a result of hydrogen peroxide formation. J. Cell Physiol. 90: 61-70.

28. Stossel, T. P., R. J. Mason, and A. L. Smith. 1974. Lipid peroxidation by human blood phagocytes. J. Clin. Invest. 54: 638-645.

29. Dobretsov, G. E., T. A. Borschevskaya, V. A. Petrov, and Y. A. Vladimirov. 1977. The increase of phospholipid bilayer rigidity after lipid peroxidation. FEBS (Fed. Eur. Biochem. Soc.) Lett. 84: 125-128.

30. Boxer, L. A., M. Rister, J. M. Allen, and R. L. Baehner. 1977. Improvement of Chediak-Higashi leukocyte function by cyclic guanosine monophosphate. Blood. 49: 9-17.

31. Weissman, G., I. Goldstein, S. Hoffstein, and P. K. Tsung. 1975. Reciprocal effects of CAMP and CGMP on microtubule-dependent release of lysosomal enzymes. Ann. N. Y. Acad. Sci. 253: 750-762.

32. Oliver, J. M. 1976. Impaired microtubule function correctable by cyclic GMP and cholinergic agonists in the Chediak-Higashi syndrome. Am. J. Pathol. 85: 395-418.

33. Bourguignon, L. Y. W., and S. J. Singer. 1977. Transmembrane interactions and the mechanism of capping surface receptors by their specific ligands. Proc. Natl. Acad. Sci. U. S. A. 74: 5031-5035. 